\title{
The Impact of Grants on Homeowner Decisions to Retrofit to Reduce Hurricane-Induced Wind and Flood Damage
}

\author{
ESTHER CHIEW \\ Department of Civil and Environmental Engineering, Cornell University, Ithaca, New York \\ RACHEL A. DAVIDSON \\ Department of Civil and Environmental Engineering, University of Delaware, Newark, Delaware \\ JOSEPH E. TRAINOR \\ School of Public Policy and Administration, University of Delaware, Newark, Delaware \\ LINDA K. NOZICK \\ Department of Civil and Environmental Engineering, Cornell University, Ithaca, New York \\ JAMIE L. KRUSE \\ Department of Economics, East Carolina University, Greenville, North Carolina
}

(Manuscript received 11 January 2019, in final form 1 October 2019)

\begin{abstract}
An increasing number of national, state, and local programs have offered grants or other monetary incentives to encourage homeowners to retrofit their homes to reduce damage from natural hazard events. Despite this fact, little is known about how these offerings influence a homeowner's decision to carry out such structural retrofits. This paper studies the impact that different grant program designs in particular have on the decision to undertake different types of retrofits to mitigate against hurricane damage. Using data from a survey of homeowners in the eastern half of North Carolina, we implement a mixed logit model that allows for the combination of both revealed-preference and stated-preference data available from the survey. Our findings show that offering a grant results in households being, on average, 3 times as likely to retrofit as when a grant is not offered. In addition, both the percentage of retrofit cost and the maximum dollar amount covered by the grant have a substantial impact on the probability that households choose to retrofit. Living closer to the coastline also has a significant impact on the probability that households will choose to retrofit. Counter to some previous research, we find that households who have experienced two or more hurricanes are less likely to choose to retrofit their homes. From our research, we find that the percentage of retrofit cost covered by the grant and the total cost are both important factors when deciding on the best grant program configuration.
\end{abstract}

\section{Introduction}

In 2017, an independent cost-benefit analysis commissioned by the Federal Emergency Management Agency (FEMA) of federally funded natural hazard mitigation efforts found that mitigating against wind damage saved $\$ 5$ for every $\$ 1$ spent (Porter et al. 2017). Mitigation measures studied included using tie-down

Corresponding author: Esther Chiew,wc437@cornell.edu straps, strengthening overhangs and openings, and strengthening connections of attached structures. Too few grants had been administered for mitigation against the effects of storm surge for FEMA to provide an accurate cost-benefit analysis. However, they found that building new houses that are elevated more than $1 \mathrm{ft}(30.5 \mathrm{~cm})$ above base flood elevation levels (the 2015 International Code Requirement) is expected to save $\$ 7$ for every $\$ 1$ spent on average (Porter et al. 2017). Despite the benefits of retrofitting, household retrofits 
historically have not been widely implemented, as many homeowners tend not to retrofit their homes voluntarily. Javeline and Kijewski-Correa (2019) surveyed homeowners living in the coastal community of New Hanover County, North Carolina, for example, and found that not only do homeowners take minimal actions to implement structural retrofits, they also have minimal intentions to do so in the future. Thus, there have been an increasing number of national and state programs that offer monetary incentives, such as grants, insurance premium benefits, or low-cost loans, to encourage homeowners to carry out home retrofits (section 2).

Despite these programs, little is known about how these monetary incentives influence homeowners' decisions to strengthen their homes postconstruction. While it seems clear that grants should increase rates of retrofit, budgets are limited, and thus it is also important to know more specifically how these incentives should be designed to maximize cost-effectiveness, and how much different levels of government investment are likely to increase retrofit and decrease risk. Is it better to offer larger grants to fewer homeowners, for example, or smaller grants to more? Should homeowners be required to pay some of the cost so as to spread government investment across more grants? One of the few studies that focused on structural retrofit incentives, Jasour et al. (2018), found evidence that a grant (which did not need to be repaid) increases the likelihood of retrofitting, but found no such evidence for incentives in the form of low-interest loans or insurance premium reductions. Based on those results, we focus on the impact of different grant program designs on the decision to undertake different types of retrofits. We also follow Jasour et al. (2018) in combining revealed-preference (RP) and statedpreference (SP) data and in developing separate mixed logit models for decisions about retrofits aimed at mitigating five different types of hurricane damage, namely, wind damage to the roof, wind damage to openings (windows and doors), wind damage to the roof-to-wall connection, flood damage to outlets and appliances or other flood damage that can be mitigated by elevating appliances or installing waterresistant insulation and siding, and flood damage to the entire house (mitigated by elevating the home on piles). The RP data relate to people's actual choices in real-world situations, whereas SP data are collected in surveys where respondents are presented with hypothetical choice situations (Train 2009). Combining these data types allows us to take advantage of both their strengths. RP data are often thought to be more reliable because they reflect actual choices. However, they are limited to existing alternatives, and even among existing alternatives there is often limited variation in attribute values (Lavasani et al. 2017). SP data, though reliant on the respondent's perception of their future actions, allow for the investigation of new grant possibilities (Lavasani et al. 2017). Our analysis is based on data obtained from a survey mailed to homeowners in the eastern half of North Carolina (from Raleigh to the coast) from January to February 2017.

Section 2 discusses several grant programs currently offered to homeowners in the United States. Section 3 outlines existing literature on homeowner decisions to retrofit their homes against hurricane-caused wind or flood damage. Section 4 identifies the covariates and hypotheses that we study in this research. In sections 5 and 6 we describe the data and model, and the results, respectively.

\section{Existing incentive programs}

There are a growing number of federal, state, and local programs that offer monetary incentives to encourage homeowners to carry out retrofits to mitigate against different hazards. These monetary incentives can take multiple forms, including grants, insurance premium deductions, and low-interest loans. The following examples illustrate the range of typical programs.

The Hurricane Loss Mitigation Program Retrofit Grant was established in Florida in 1997. With an annual budget of up to $\$ 3.4$ million, it funds activities (including retrofits, inspections, construction, and modification of building components) that would increase a structure's ability to withstand hurricane-force winds and flooding (Florida Division of Emergency Management 2018). From 1997 to 2014, at least 138 grants have been issued for residential retrofit projects, with retrofits implemented on an estimated 2217 homes and costing around \$18 million (Florida Division of Emergency Management 2014).

Under the South Carolina Safe Home program, homeowners living in the coastal region of South Carolina who retrofit their homes to be more resistant to hurricane and high-wind damage can obtain a grant of up to $\$ 5,000$ (South Carolina Department of Insurance 2018). Eligible retrofits include roof retrofits (such as roof-to-wall connectors) and opening protection. Homeowners with a higher annual household income can be awarded a matching grant (i.e., the homeowner has to match the grant award dollar for dollar) of up to $\$ 4,000$. The Safe Home program receives about $\$ 2$ million in annual funding, and since its beginning in 2007, the program has awarded more than 6100 grants totaling more than \$25 million (South Carolina Department of Insurance 2019). 
In Alabama, the Strengthen Alabama Homes Program provides grants for residential wind mitigation on existing, owner-occupied, single-family homes that meet the "FORTIFIED" mitigation standards developed by the Insurance Institute for Business and Home Safety (IBHS). Previously restricted to residents of Baldwin and Mobile Counties, the program is now open to the entire state. Grants pay $100 \%$ of the cost of mitigation up to $\$ 10,000$ (Alabama Department of Insurance 2018), and the program aims to provide grants to 2500 homes annually, and 50000 homes over the next 20 years (Alabama Association of Realtors 2019). Homes that meet the FORTIFIED standards also receive discounts ranging from $20 \%$ to $60 \%$ on the wind portion of their homeowner's insurance premium (Alabama Department of Insurance 2014). Other states, such as Mississippi and North Carolina, also offer insurance premium savings to homeowners who retrofit their homes to meet FORTIFIED standards (IBHS 2018).

For homeowners who voluntarily retrofit their residential structures against storms, Louisiana offers tax deductions of $50 \%$ of the cost of retrofit up to $\$ 5,000$ (Louisiana Department of Insurance 2005). Though not related to hurricanes, individuals in Colorado who perform wildfire mitigation measures on their property can claim a deduction on their income tax return equal to $50 \%$ or $100 \%$ of the cost of mitigation (depending on the tax year), up to $\$ 2,500$ (Colorado Department of Revenue 2018).

As can been seen, there is a growing interest in incentivizing home retrofit work. However, in offering monetary incentives to homeowners, it is not clear what grant specifications generates the most interest or results in the greatest take up rates in different circumstances. Parameters chosen to specify the grants in our survey were based on these examples [section 5a(1)].

\section{Literature review}

The existing literature that addresses the homeowner's decision to implement structural retrofits against hurricane damage are few and varied in focus. Peacock (2003) and Grothmann and Reusswig (2006) study the extent to which structural retrofits are used to mitigate against wind and flood damage, respectively. Other authors including Petrolia et al. (2015) and Thieken et al. (2006) include insurance as a choice alongside structural retrofits to homes. More similar to the study presented herein, several papers examine the influence of incentives (both monetary and nonmonetary) on the household's decision to retrofit, including Vásquez and Mozumder (2017), Poussin et al. (2013, 2014), Ge et al. (2011), and Jasour et al. (2018). However, while the availability and type of incentives has been studied, there is little know about the impact of different grant program designs (such as the maximum grant amount or percentage of retrofit cost covered by the grant) on the decision to retrofit. This paper analyzes this question in detail.

Most of the papers study the decision to implement retrofits using a regression model with the decision variable being the choice to carry out some mitigation effort (whether purchasing insurance or carrying out retrofits), the number of structural retrofits installed by a homeowner, or the decision to participate in programs designed to encourage mitigation efforts. All but Vásquez and Mozumder (2017), Ge et al. (2011), Poussin et al. (2014), and Jasour et al. (2018) utilized RP data in the analysis, with the former two studies employing SP data and the latter two studies combining both RP and SP data. This study combines RP and SP data in order to take advantage of the strengths of both types of data, and also demonstrates the importance of using both RP and SP data to study this problem.

Collectively, the current research has identified many factors that may influence a homeowner's decision to carry out structural retrofits to their home, including 1) type or availability of incentive (e.g., reduced insurance deductibles or premiums, reduced taxes, loans, or free home audits), 2) hazard experience (e.g., prior exposure to hurricanes or having suffered damage from hurricanes), 3) psychological factors (e.g., risk perception, risk attitudes, or worry), 4) social influences (e.g., mitigation measures taken by neighbors or friends; regulations), and 5) socioeconomic factors (e.g., income, age, or gender). In section 4 , we focus on the studies directly related to the covariates that are used in this study.

In keeping with the analysis of this paper that focuses on structural retrofits, we do not include either the theoretical economics literature, which mostly assumes utilitybased decisions [e.g., work based on Ehrlich and Becker (1972)], or the broader protective action decision literature that focuses on preparedness, insurance purchase, and other types of protective actions that may be of a different character than permanent structural retrofits (e.g., Lindell and Perry 2012; Kunreuther 2016; McAneney et al. 2016; Kousky 2017; Wang et al. 2017; Binder and Greer 2016).

\section{Covariates and hypothesis}

In this section we describe the covariates selected for the model. The choice of covariates used is based on a review of the existing literature, as summarized in Table 1.

\section{a. Incentives}

Jasour et al. (2018) found that offering a grant is associated with an increased probability of carrying out a 


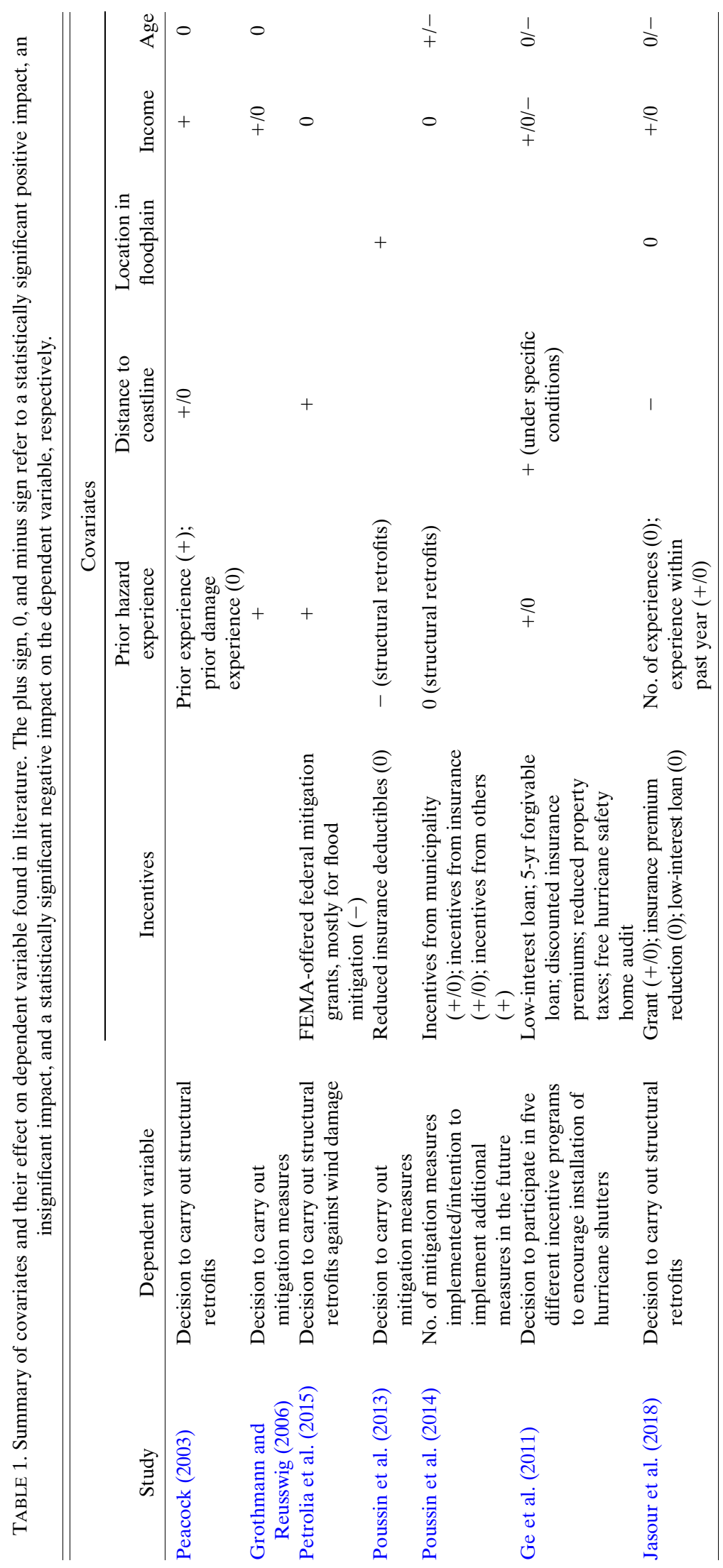


retrofit to mitigate against wind damage caused by hurricanes, though not for mitigating against flood damage. Neither offering a premium reduction nor offering a low interest loan was found to have a significant effect on the probability of retrofit. Ge et al. (2011) considered incentives as a response variable rather than a covariate in their models; however, survey respondents were asked about the likelihood that each economic incentive would motivate them to undertake a hurricane mitigation measure, and Ge et al. (2011) reported that some homeowners would likely be motivated to install hurricane shutters in response to a low-interest loan (31\%), a 5-yr forgivable loan (60\%), reduced home insurance premiums $(69 \%)$, reduced property taxes $(69 \%)$, and a free hurricane safety home audit $(68 \%)$. Poussin et al. (2014) found that offering financial incentives to homeowners resulted in greater intention to implement mitigation measures, though no details were provided about how the financial incentives were given to homeowners. Vásquez and Mozumder (2017) found that respondents had a strong preference for matching grants and conditional insurance premium discounts rather than extensive home inspections. Petrolia et al. (2015) found that the increase of county-level federal mitigation grants offered for flood mitigation had a significantly negative impact on the decision to carry out structural retrofits to prevent wind damage, perhaps indicating that flood mitigation is being seen as a substitute for wind mitigation efforts.

From Jasour et al. (2018), in this study, we focus on incentives in the form of grants and, in particular, on the impact that different ways of structuring grants has on the decision of homeowners to retrofit their homes. On the basis of a review of existing grant programs (section 2), two parameters are used to define the structure of a grant program - the percentage of the retrofit cost covered by the grant and the maximum dollar amount provided by the grant. Two hypotheses are tested:

Hypothesis 1-As the percentage of the retrofit cost that is covered by the grant increases, the probability that the homeowner chooses to implement a structural retrofit also increases (H1).

Hypothesis 2-As the maximum dollar amount provided by the grant increases, the probability of implementing a retrofit also increases $(\mathrm{H} 2)$.

\section{b. Prior hazard experience}

Peacock (2003), Grothmann and Reusswig (2006), and Petrolia et al. (2015) found that prior hazard experience positively impacts the decision to retrofit. Ge et al. (2011) found that prior hazard experience increases the probability of accepting a low-interest loan, but not any of the other incentives, specifically the 5-yr forgivable loan, reduced home insurance premiums, reduced property taxes, or free hurricane safety home audit. In contrast, Poussin et al. (2014) found no significant effect of prior hazard experience on the decision to retrofit. Jasour et al. (2018) found no evidence that the number of hurricanes experienced by a household affects the decision to retrofit. However, their results suggest that having experienced a hurricane within the past one year has a significant positive effect on the decision to implement retrofits to strengthen the home against flood and opening damage. In this research, we were unable to study the impact that time since the last event has on the probability of retrofitting because almost all the households experienced Hurricane Matthew in 2016, and thus we could not make the same distinctions between households that Jasour et al. (2018) studied. As such, we instead study the impact that the number of hurricanes experienced has on the probability that a household decides to undertake a structural retrofit:

Hypothesis 3-As the number of hurricanes experienced increases, the probability that a household retrofits their home also increases $(\mathrm{H} 3)$.

\section{c. Exposure/location factors}

Peacock (2003), Petrolia et al. (2015), and Ge et al. (2011) found evidence that households located in a coastal county are more likely to retrofit their homes to prevent wind damage. However, Peacock (2003) found no evidence that being in an evacuation zone (the most at-risk households) had any effect on the likelihood of retrofitting, and Ge et al. (2011) only found evidence of this location effect when risk perception and hazard intrusiveness variables were not included in the model. Poussin et al. (2013) found that households living in an area with less frequent floods were less likely to carry out structural measures on their homes. Jasour et al. (2018) studied separately the effect that being located closer to the coastline and in a floodplain would have on the probability of retrofitting, and found that in all four retrofit models, households located farther from the coastline are significantly less likely to retrofit their homes. However, being located in a floodplain had no significant effect on the decision to retrofit. For this research, we examine the effects that the home's distance from the coastline has on the decision to undertake a structural retrofit of the house. We also examine whether a home's location in a floodplain influences the decision to implement a structural retrofit that would mitigate against flood damage, that is, 
either by elevating appliances and outlets or installing water-resistant insulation and siding, or by elevating the entire home on piles. From this, two hypotheses are tested:

Hypothesis 4-The shorter the distance from the coastline, the higher the probability that the household carries out retrofits (H4).

Hypothesis 5-If the home is located in a floodplain, the household is more likely to retrofit to reduce flood damage (H5).

\section{d. Sociodemographic factors}

Income has mostly been found to have a significant positive effect on the likelihood that a household carries out structural retrofits to mitigate against hurricane damage. Peacock (2003) found that households with higher incomes are not only more likely to install hurricane shutters, but also to have better quality shutters and envelope coverage than lower-income households. Grothmann and Reusswig (2006) find a significant positive impact of household income on the decision to purchase flood protection devices, but not on structural measures of mitigation. Jasour et al. (2018) found a significantly positive effect only on the likelihood of mitigating against wind damage to the roof. Ge et al. (2011) find that higher-income households have significantly less interest in lowinterest loans for mitigation, and significantly more interest in property tax reductions for mitigation as compared to low-income households. Finally, Petrolia et al. (2015) and Poussin et al. (2014) find no significant impact of income on the likelihood that households implement structural retrofits, although the coefficient of income that Petrolia et al. (2015) estimated is positive (Poussin et al. (2014) do not report this coefficient).

Other sociodemographic variables can help to identify sectors of the population that are most or least likely to carry out structural retrofits on their homes (Peacock 2003; Ge et al. 2011). To further aid in the identification of these population sectors, in this research, we analyze two variables: age and the number of years that the resident believes they will remain in their home (hereinafter referred to as future tenure). Older homeowners might be less likely to retrofit because they are more likely to be on a fixed income, thus less willing to take on financial risk (Ge et al. 2011). However, previous research shows mixed results. Age had a significantly positive effect on past mitigating behavior but a significantly negative effect on intentions to carry out future mitigation measures in Poussin et al. (2014), a significantly negative effect in Ge et al. (2011), and an insignificant effect in Peacock (2003) and Grothmann and Reusswig (2006). Jasour et al. (2018) found age to have a significantly negative effect on the likelihood of mitigating against wind damage to roof and flood damage only, and an insignificant impact on other retrofit decisions. Future tenure has not been studied in previous literature, but homeowners who believe they have a longer expected future tenure in their home might be more likely to retrofit as they would have a longer time to reap the benefits of any retrofits that are carried out. From these points, three more hypotheses are developed:

Hypothesis 6-Income has a positive effect on the likelihood that a household carries out a structural retrofit (H6).

Hypothesis 7-Younger homeowners are more likely to retrofit their homes $(\mathrm{H} 7)$.

Hypothesis 8-Homeowners who have a longer expected future tenure in the home are more likely to retrofit their home (H8).

\section{Method}

\section{a. Survey data}

The data used in this analysis are taken from a survey of single-family households located in the eastern half of North Carolina, from the capital of Raleigh to the coast, including 49 of the state's 100 counties. The region was chosen because it has a long history of damaging hurricanes, with a tropical cyclone making landfall on average every 2 years (SCONC 2019). It has also been active in encouraging mitigation-for example, offering wind insurance premium discounts for mitigation efforts through the Coastal Property Insurance Pool (i.e., Beach Plan) (NCIUA 2017). The survey sample was purchased from Genesys, a branch of the Marketing Systems Group, which utilizes the U.S. Postal Service's address database system to select random addresses for research purposes (Marketing Systems Group 2018). From this address database system, 2500 randomly selected addresses were purchased and screened to include only single-family, owner-occupied properties.

In an effort to achieve high survey response rates, the survey was distributed following the Dillman (2007) procedures. These procedures included the development of a respondent-friendly survey, four contacts through first-class mail, stamped return envelopes, personalization of correspondence, and prepaid financial incentives (Dillman 2007). To be eligible to participate, respondents had to be at least 18 years old, own the property to which the survey was mailed, and contribute to the household's property insurance and home-improvement decision-making process. 
The dataset includes 233 completed surveys after removing ineligible responses.

Relative to the demographics for the population from which it was drawn-homeowners in the eastern half of North Carolina, our sample was slightly older and whiter. Since the average age of first-time homebuyers in 2017 was 32 years (Ramirez 2017), we assume homeowners include only people aged $30+$ years. The average age in our sample was then 59 years, as compared with 54 years in the population. The sample was $81 \%$ white versus $67 \%$ for the population. Table 2 shows the calculated American Association for Public Opinion Research (AAPOR) response rate values (AAPOR 2019). The minimum response rate, comparing number of completed surveys with eligible households in the sample, is $10 \%$. On the other hand, the cooperation rate, comparing completed surveys to households with confirmed contact, is $90 \%$ (Table 2), suggesting that a large driver was noncontact, a well-known problem.

\section{1) RESPONSE VARIABLE}

A binary response variable was used for this analysisretrofit or not. To collect RP observations of the response variables, survey respondents were asked if their home has each of the following eight features: wind-resistant shingles, special foam adhesive under the roof, hurricane shutters, impact-resistant windows, hurricane straps/ties, elevated appliances, water-resistant siding, and piles that elevate their home. For each feature, if the respondent indicated that the home does have it and that either they added it after they bought the home or it was important to them when they bought the home, the response was coded as Yes. If the respondent indicated the home does not have the feature, they do not know if it does, or it does but it was not important to them when they bought the home, the response was coded as No.

Two questions were used to collect the SP observations of the response variables. The first, followed by a list of the same eight features from the RP question, said "we would like you to imagine that you moved to a new home that did not have any of the following features. With that assumption, tell us if you would add each feature within five years." Respondents were asked to respond "yes," "no," or "maybe" to adding each of the eight features within the next $5 \mathrm{yr}$. The next question read: "Imagine again that you moved to a new home without any of these features and now you could receive a grant from the government to strengthen your home. The grant would not need to be repaid. Would you take each action below within five years given the grant terms listed?" It was then followed by a list of five possible retrofits, and for each, a list of six possible grant
TABLE 2. AAPOR calculations.

\begin{tabular}{ccc}
\hline \hline & Response rate & \\
& & AAPOR 1 \\
& & \\
& Refusal rate & \\
& & AAPOR 1 \\
AAPOR 6 & & $1.07 \%$ \\
$7.37 \%$ & Contact rate & \\
& & AAPOR 1 \\
AAPOR 6 & & $16.80 \%$ \\
$84.00 \%$ & Cooperation rate & \\
& $90.35 \%$ & \\
\hline
\end{tabular}

terms-all combinations of the government paying $50 \%$ or $100 \%$ of the cost, up to a maximum amount of $\$ 2,500, \$ 5,000$ or $\$ 10,000$ (Table 3).

The combination of grant terms resulted in seven SP choice situations for each type of retrofit. The five possible retrofits were the same eight from the previous questions, but to shorten the survey, the two roof retrofits were combined ("Strengthen your roof with high wind shingles or special adhesive foam"), the two opening retrofits were combined ("Protect the openings in your home by installing impact resistant windows or hurricane shutters, and reinforcing garage doors"), and the two less expensive flood retrofits were combined ("Protect against flood damage by elevating outlets and appliances above flood level, or installing water resistant insulation and siding"). Survey respondents answered either Yes or No to the question about whether they would carry out each type of retrofit (Table 3). To combine the RP and SP responses, the five retrofit type definitions were used-roof, openings, straps, outlets/siding (i.e., elevating outlets and appliances or installing water-resistant insulation and siding), and piles. For the RP question and the SP question with no grant, if the respondent indicated yes to either feature, it was coded as Yes. Note that, unlike in the survey data used in Jasour et al. (2018), all respondents were asked the SP questions and not only those who indicated it had not been done in the RP question, and thus the coding differs.

Of the 233 responses, there were from 213 to $219 \mathrm{RP}$ observations, and from 179 to 217 SP observations, depending on the retrofit type and grant parameter values (Table 3). Since few respondents (between $5 \%$ and $18 \%$ ) had installed any retrofits, and fewer still (3 of 233 individuals) had any knowledge of grant availability at the time of installation, we assume in our models that RP retrofits were conducted without a grant. However, including the RP observations not only provides us with additional information of which homeowners installed 
TABLE 3. Number of RP and SP responses for each type of retrofit and grant alternative.

\begin{tabular}{|c|c|c|c|c|c|c|c|c|}
\hline \multirow[b]{2}{*}{ Data type } & \multicolumn{2}{|c|}{ Grant alternative } & \multirow[b]{2}{*}{ Response } & \multicolumn{3}{|c|}{ Wind } & \multicolumn{2}{|l|}{ Flood } \\
\hline & $\begin{array}{l}\text { Percentage government } \\
\text { pays } x_{\text {GrantPerc }}\end{array}$ & $\begin{array}{c}\text { Max } \\
\text { amount } x_{\text {MaxGrant }}\end{array}$ & & Roof & Openings & Straps & Outlets/siding & Piles \\
\hline \multirow[t]{2}{*}{$\mathrm{RP}$} & $0 \%$ & 0 & Yes & 39 & 32 & 32 & 35 & 10 \\
\hline & & & No & 180 & 181 & 184 & 181 & 204 \\
\hline \multirow[t]{14}{*}{ SP } & $0 \%$ & 0 & Yes & 75 & 95 & 46 & 67 & 14 \\
\hline & & & No & 141 & 122 & 168 & 149 & 202 \\
\hline & $50 \%$ & $\$ 2,500$ & Yes & 50 & 58 & 51 & 32 & 27 \\
\hline & & & No & 131 & 124 & 134 & 156 & 159 \\
\hline & $100 \%$ & $\$ 2,500$ & Yes & 92 & 99 & 81 & 64 & 45 \\
\hline & & & No & 97 & 90 & 105 & 124 & 141 \\
\hline & $50 \%$ & $\$ 5,000$ & Yes & 64 & 64 & 48 & 34 & 23 \\
\hline & & & No & 115 & 115 & 131 & 151 & 162 \\
\hline & $100 \%$ & $\$ 5,000$ & Yes & 127 & 117 & 96 & 77 & 58 \\
\hline & & & No & 66 & 73 & 94 & 114 & 131 \\
\hline & $50 \%$ & $\$ 10,000$ & Yes & 66 & 66 & 50 & 38 & 35 \\
\hline & & & No & 116 & 114 & 129 & 146 & 151 \\
\hline & $100 \%$ & $\$ 10,000$ & Yes & 155 & 158 & 127 & 110 & 96 \\
\hline & & & No & 44 & 42 & 71 & 91 & 104 \\
\hline
\end{tabular}

retrofits, it also allows us to obtain the current market equilibria concerning homeowner's probability of installing retrofits.

\section{2) Covariates}

In addition to the percentage of retrofit cost the government would pay $x_{\text {GrantPerc }}$ and the maximum grant amount $x_{\text {MaxGrant }}$ (Table 3 ), other covariates were chosen by surveying the literature to ensure that we controlled for key factors (section 4). They were also restricted in number (to avoid overspecification) and to avoid including highly correlated covariates. Tables 4 and 5 provide the descriptive statistics of the covariates included in the models.

Distance to coastline $x_{\mathrm{dist}}$ and location in floodplain $x_{\mathrm{fp}}$ were determined by geocoding street addresses and computing in GIS. The former was computed as straight-line nearest distance to the coastline, and the latter was computed by overlaying households on 100-yr FEMA flood insurance rate maps. Location in floodplain $x_{\mathrm{fp}}$ is only included in the retrofit models for flood damage, as we hypothesize that being in a floodplain should have minimal influence on the wind damage to a house. (Preliminary analyses that included $x_{\mathrm{fp}}$ suggested that the variable was not significant in the wind retrofit models, thus supporting that assumption.) Number of hurricanes experienced $x_{\text {num }}$ was coded categorically to reflect the assumption that there is a big difference between having at least two experiences versus one or no experiences. We chose two experiences as the dividing point because most of the survey respondents had been living in the area since at least 2016, and thus had experienced Hurricane Matthew. This value was based on the year that the homeowner stated they began living in the area (in answer to the question "About what year did you start living in the eastern half of North Carolina?") and historical information about when hurricanes affected North Carolina during that time. Of 214 people who responded to the question "About how many more years do you expect to own your current home?," 49 (23\%) responded with Forever, and so we coded the variable future tenure categorically to reflect the difference between those homeowners who expect to

TABLE 4. Descriptive statistics for continuous covariates.

\begin{tabular}{|c|c|c|c|c|}
\hline Variable & Hypothesized effect ${ }^{\mathrm{a}}$ & No. of respondents & Mean & Std dev \\
\hline$x_{\text {dist }}($ distance to coastline $; \mathrm{km})$ & Negative & 233 & 99.59 & 69.62 \\
\hline$x_{\text {inc }}\left(\right.$ income $^{\text {b }} ; \$ 1,000$ s per year) & Positive & 196 & 98.74 & 74.54 \\
\hline$x_{\text {age }}($ age; yr) & Negative & 217 & 58.97 & 14.97 \\
\hline
\end{tabular}

${ }^{a}$ Positive means that an increase in the covariate is associated with an increase in the probability of carrying out a retrofit.

${ }^{\mathrm{b}}$ Income was asked in the survey as an interval variable but was coded in the model as a continuous variable with the values in parentheses for each interval: $\$ 0-\$ 15,000(\$ 7,500), \$ 15,000-\$ 35,000(\$ 25,000), \$ 35,000-\$ 50,000(\$ 42,500), \$ 50,000-\$ 75,000(\$ 62,500), \$ 75,000-$ $\$ 100,000(\$ 87,500), \$ 100,000-\$ 150,000(\$ 125,000), \$ 150,000-\$ 250,000(\$ 200,000)$, and more than $\$ 250,000(\$ 300,000)$. 
TABLE 5. Descriptive statistics for discrete covariates.

\begin{tabular}{|c|c|c|c|c|}
\hline & Variable & Hypothesized effect $^{\mathrm{a}}$ & Levels & No. of respondents \\
\hline \multirow[t]{2}{*}{$x_{\text {num }}$} & \multirow[t]{2}{*}{ No. hurricanes experienced } & \multirow[t]{2}{*}{ Positive } & 1: two or more & 216 \\
\hline & & & 0 : zero or one & 10 \\
\hline \multirow[t]{2}{*}{$x_{\mathrm{fp}}$} & \multirow[t]{2}{*}{ Location in floodplain } & \multirow[t]{2}{*}{ Positive } & 1: in floodplain & 24 \\
\hline & & & $0:$ not in floodplain & 209 \\
\hline \multirow[t]{2}{*}{$x_{\text {futtenure }}$} & \multirow{2}{*}{$\begin{array}{l}\text { Length of time individual expects to stay } \\
\text { in their current home }\end{array}$} & \multirow[t]{2}{*}{ Positive } & 1: forever & 49 \\
\hline & & & 0 : otherwise & 165 \\
\hline
\end{tabular}

${ }^{a}$ Positive means that an increase in the covariate is associated with an increase in the probability of carrying out a retrofit.

live in their homes until the end of their lives (forever) versus those who see an end to their stay in that house.

\section{b. Multiple imputation}

From the 233 respondents, data were missing in a patchwork, not monotone, pattern. As a result, we used multiple imputation to address the issue. Using listwise or pairwise deletion of data would have resulted in the removal of too many observations and could produce potentially biased coefficient estimates (Harrell 2015). Multiple imputation imputes $m$ new values for each missing value in the data, resulting in $m$ complete datasets, and unlike single imputation, multiple imputation accounts for uncertainty around imputed data.

Using the package "mice" in the $R$ software package (van Buuren and Groothuis-Oudshoorn 2011; van Buuren 2012), we generated $m=7$ imputed datasets. As recommended by Harrell (2015) and White et al. (2011), we used all variables as predictors (including the response variables), and the algorithm was set for 30 iterations. However, the missing data in the response variables were not imputed, and observations with missing response variables were not used in the model estimation. The default settings of the software were used, that is, logistic regression for the binary variables and predictive mean matching for the other variables. Each of the seven datasets were analyzed separately, and then their results were combined to create one final pooled result using Rubin's rules (van Buuren 2012; White et al. 2011; Miles 2016).

\section{c. Combining RP and SP data: The mixed logit model}

The process of combining RP and SP data and estimating a model from the pooled data has been used extensively in the marketing and transportation research fields (Whitehead et al. 2008). RP data, which reflect actual market choices, can help identify market shares (Hensher et al. 2015) and are used to obtain the current market equilibria (Swait et al. 1994). However, the trade-off information between different attributes may be deficient because of a lack of market availability: RP studies are, by definition, limited to existing alternatives (Louviere et al. 2000; Lavasani et al. 2017). The SP studies can overcome this weakness by gathering responses to new choice situations (Lavasani et al. 2017; Swait et al. 1994). However, using SP data on their own can give implausible forecasts (Brownstone et al. 2000).

Combining RP and SP data is often used to test a consumer's response to new alternatives (Bhat and Castelar 2002; Brownstone et al. 2000; Hensher et al. 2008). It is also used to investigate how people's choices will change given new choice situations (attributes) or information (Boxall et al. 2003; Börjesson 2008). In this analysis, the SP survey questions provide new choice situations (six possible grant terms) in which respondents are asked whether or not they would implement home structural retrofits.

Although combining RP and SP data is beneficial, there are technical issues that need to be addressed. The model applied to the survey data is a discrete choice mixed logit model. The mixed logit allowed us to combine the benefits of RP and SP data and to account for the following three important issues (Hensher and Bradley 1993; Hensher et al. 2008). First, because each respondent is asked multiple questions (an RP and multiple SP questions), the choice sets might potentially exhibit correlation, and the mixed logit model is able to account for this panel data (compared to a nested logit model). Second, joint estimation of RP and SP data causes a potential "state dependence" effect, because the actual choice made (as captured in RP data) can influence a person's choice in hypothetical situations (as captured in SP data). It is possible that the state dependence might be positive for some individuals and negative for others (Bhat and Castelar 2002). Third, scale differences may exist between RP and SP data. Since RP and SP choices are made under different circumstances, both of which contain factors unobserved by the analyst that can influence choice, there is no reason to believe that the variance of the unobserved factors in each of these settings will be the same (Bhat and Castelar 2002). There is no a priori theoretical basis to suggest whether the RP error term 
or the SP error term will have a larger variance, but the model should account for their differences.

The full formulation of the mixed logit model is given as in Bhat and Castelar (2002) and Hensher et al. (2008). Equations (1) and (2) are the models for the utility associated with retrofitting against flood damage for individual $i$ choosing alternative $j=$ Yes and $j=$ No, respectively, in choice situation $t$ [the equivalent model for the utility associated with retrofitting against wind damage (i.e., roof, openings, and straps) is similar, except that it does not include the covariate of the location in a floodplain $\left(x_{\mathrm{fp}}\right)$, which accounts for flood damage]:

$$
\begin{aligned}
U_{i j t}= & \mathrm{ASC}_{i j}+\beta_{\mathrm{GrantPerc}} x_{\mathrm{GrantPerc}, i j t}+\beta_{\mathrm{MaxGrant}} x_{\mathrm{MaxGrant}, i j t}+\beta_{\mathrm{num}} x_{\mathrm{num}, i}+\beta_{\mathrm{dist}} x_{\mathrm{dist}, i}+\beta_{\mathrm{fp}} x_{\mathrm{fp}, i}+\beta_{\mathrm{inc}} x_{\mathrm{inc}, i} \\
& +\beta_{\mathrm{age}} x_{\mathrm{age}}+\beta_{\text {futtenure }} x_{\text {futtenure }, i}+\varphi_{i}\left[\left(1-\kappa_{\mathrm{RP}, i t}\right)\left(\sum_{s=1}^{T_{i}} \kappa_{\mathrm{RP}, i s} Y_{i j s}\right)\right]+\varepsilon_{i j t}, \quad \text { for } j=\mathrm{Yes} \quad \text { and } \\
U_{i j t}= & \varphi_{i}\left[\left(1-\kappa_{\mathrm{RP}, i t}\right)\left(\sum_{s=1}^{T_{i}} \kappa_{\mathrm{RP}, i s} Y_{i j s}\right)\right]+\varepsilon_{i j t}, \text { for } j=\mathrm{No}
\end{aligned}
$$

where $U_{i j t}$ is the utility of individual $i$ choosing alternative $j$ in choice situation $t, \mathrm{ASC}_{i j}$ are alternativespecific constants (ASCs), $x_{\mathrm{GrantPerc}, i j t}$ is the percentage of the cost that the government would pay to individual $i$ choosing alternative $j$ in choice situation $t, x_{\text {MaxGrant }, i j t}$ is the maximum value of the grant in thousands of dollars that the government would pay to individual $i$ choosing alternative $j$ in choice situation $t, \varphi_{i}$ is the individual-specific state-dependence effect that maps the effect of the RP choice of an alternative into the utility evaluation of that alternative in the SP choice situation, $\kappa_{\mathrm{RP}, i t}$ is a dummy variable that is equal to 1 if $t$ is an RP choice situation for individual $i$ and 0 if not, $Y_{i j s}$ is a binary variable with value 1 if individual $i$ chooses alternative $j$ in the $s$ th choice situation and 0 otherwise, $T_{i}$ is the total number of observed choice situations for individual $i$, and $\varepsilon_{i j t}$ is an unobserved random term. All other covariates have been defined in section 5 a.

State dependence is defined by the term

$$
\varphi_{i}\left[\left(1-\kappa_{\mathrm{RP}, i t}\right)\left(\sum_{s=1}^{T_{i}} \kappa_{\mathrm{RP}, i s} Y_{i j s}\right)\right]
$$

in Eqs. (1) and (2). Note that for each RP choice situation, since $\kappa_{\mathrm{RP}, i t}=1$, the entire term reduces to zero. In addition, the summation is 1 if individual $i$ chose alternative $j$ in the RP situation and 0 otherwise. Thus, the term as a whole has the effect of adding $\varphi_{i}$ to the utility equation for alternative $j$ in each SP choice situation if individual $i$ chose $j$ in the RP choice situation; it has no effect on any other utilities.

To address the issue of scale differences between the RP and SP choice situations, the scale parameter of the $\mathrm{RP}$ dataset is normalized to 1 , and the scale parameter of the SP data $\lambda_{i t}$ is defined as

$$
\lambda_{i t}=\left[\left(1-\kappa_{\mathrm{RP}, i t}\right) \lambda\right]+\kappa_{\mathrm{RP}, i t},
$$

where $\lambda$, the SP scale relative to RP, is estimated. In the mixed logit model, $\lambda$ is estimated by introducing a set of ASCs into the SP data that have zero mean and free variance $\sigma_{\text {SP }}$ (Hensher et al. 2008; Hensher et al. 2015). Then, $\lambda=\pi /\left(6^{1 / 2} \sigma_{\mathrm{SP}}\right)$ is inversely proportional to the estimated standard deviation of the dummy variable of the SP choice situation $\sigma_{\mathrm{SP}}$, according to the extreme value type-I distribution (Hensher et al. 2008).

With these utility evaluations, the probability that individual $i$ chooses to retrofit his home in choice situation $t$ is (Train 2009)

$$
P\left(y_{i t}=\text { Yes }\right)=\frac{\exp \left(U_{i, j=\text { Yes }, t}\right)}{\exp \left(U_{i, j=\text { Yes }, t}\right)+\exp \left(U_{i, j=\text { No }, t}\right)} .
$$

The discrete choice models were fitted using the package "gmnl" in $R$. Results from the imputed dataset were pooled using $R$ and Microsoft, Inc., Excel.

\section{Results}

\section{a. Model fit}

Table 6 summarizes the results of the retrofit decision model for each of the five damage types. It shows that the mean of the state-dependence variable $\varphi_{i}$ is significantly positive in all damage models except roof $(p<$ 0.05 for openings and outlets/siding models, and $p<0.01$ for straps and piles models). This indicates that if the homeowner had previously retrofitted their home (revealed preference), then they were more likely to state that they would carry out retrofits in stated-preference choice situations. Similarly, if they had chosen not to retrofit their homes in the past, then they were less likely 
TABLE 6. Results of retrofit decision models for different damage types.

\begin{tabular}{|c|c|c|c|c|c|c|c|c|c|c|}
\hline \multirow[b]{2}{*}{ Covariate } & \multicolumn{2}{|c|}{ Roof } & \multicolumn{2}{|c|}{ Openings } & \multicolumn{2}{|c|}{ Straps } & \multicolumn{2}{|c|}{ Outlets/siding } & \multicolumn{2}{|c|}{ Piles } \\
\hline & Coef $^{a}$ & $p$ value & Coef & $p$ value & Coef & $p$ value & Coef & $p$ value & Coef & $p$ value \\
\hline ASC: "Yes"-RP & 18.015 & 0.961 & 15.325 & 0.947 & 16.758 & 0.932 & 17.431 & 0.957 & 17.240 & 0.862 \\
\hline \multicolumn{11}{|c|}{ Grant characteristics } \\
\hline Grant percentage $x_{\text {GrantPerc }}$ & $3.035 * * *$ & 0.000 & $2.631 * * *$ & 0.000 & $4.051 * * *$ & 0.000 & $2.261 * * *$ & 0.000 & $5.033 * * *$ & 0.000 \\
\hline Max grant value $x_{\text {MaxGrant }}$ & $0.111 * * *$ & 0.000 & $0.079 * * *$ & 0.001 & $0.109 * * *$ & 0.000 & $0.047 *$ & 0.074 & $0.238 * * *$ & 0.000 \\
\hline \multicolumn{11}{|c|}{ Other characteristics } \\
\hline No. of hurricanes $x_{\text {num }}$ & $-1.228 * *$ & 0.030 & -0.604 & 0.275 & $-1.520 * *$ & 0.027 & -0.680 & 0.345 & $-1.856^{*}$ & 0.090 \\
\hline Distance from coastline $x_{\text {dist }}$ & $-0.006^{* *}$ & 0.021 & $-0.006 * * *$ & 0.004 & $-0.011 * * *$ & 0.001 & $-0.007 * * *$ & 0.010 & $-0.015^{* * *}$ & 0.007 \\
\hline Location in floodplain $x_{\mathrm{fp}}$ & & & & & & & -0.713 & 0.315 & 0.618 & 0.557 \\
\hline Income $x_{\text {inc }}$ & 0.000 & 0.979 & 0.000 & 0.836 & 0.002 & 0.526 & -0.003 & 0.298 & -0.002 & 0.686 \\
\hline Age $x_{\text {age }}$ & $-0.019 * *$ & 0.036 & $-0.017 * *$ & 0.048 & $-0.020^{*}$ & 0.079 & $-0.025 * *$ & 0.024 & $-0.052 * * *$ & 0.007 \\
\hline Future tenure $x_{\text {futtenure }}$ & 0.440 & 0.353 & 0.242 & 0.552 & 0.095 & 0.874 & 0.513 & 0.293 & 1.298 & 0.183 \\
\hline \multicolumn{11}{|c|}{ State-dependence effects $\varphi_{i}$} \\
\hline Mean & 0.204 & 0.416 & $0.566^{* *}$ & 0.026 & $1.654 * * *$ & 0.000 & $0.621 * *$ & 0.032 & $2.270 * * *$ & 0.003 \\
\hline Std dev & 0.680 & 0.305 & 0.507 & 0.432 & 0.846 & 0.427 & 0.192 & 0.797 & 1.010 & 0.469 \\
\hline \multicolumn{11}{|c|}{ SP-to-RP scale factor } \\
\hline Std dev of SP ASC & $2.547 * * *$ & 0.000 & $2.412 * * *$ & 0.000 & $3.151 * * *$ & 0.000 & $2.769 * * *$ & 0.000 & $3.957 * * *$ & 0.000 \\
\hline SP scale relative to RP $\lambda$ & 0.503 & & 0.532 & & 0.407 & & 0.463 & & 0.324 & \\
\hline Sample size & 1558 & & 1550 & & 1547 & & 1569 & & 1562 & \\
\hline McFadden pseudo $R^{2}$ & 0.328 & & 0.314 & & 0.429 & & 0.332 & & 0.451 & \\
\hline
\end{tabular}

${ }^{\text {a }}$ The symbols *, **, and *** indicate significance levels of $0.1,0.05$ and 0.01 respectively.

to state that they would carry out retrofits. The standard deviation of the state-dependence variable was not statistically significant, indicating a lack of evidence that the state-dependence effect differs across individuals. The SP scale parameter (relative to RP) was not only significantly positive but also less than one in all five hurricane damage models $\left(\lambda_{\text {Roof }}=0.503, \lambda_{\text {Openings }}=0.532, \lambda_{\text {Straps }}=0.407\right.$, $\lambda_{\text {Outlets/Siding }}=0.463$, and $\lambda_{\text {Piles }}=0.324$ ), indicating that the error variance in the SP choice situation is higher than in the RP choice situation. This shows that the unobserved factors affecting RP and SP choices are different and should be accounted for.

\section{b. Impact of incentives}

One of the main focuses of this research is to analyze how incentives, and in particular, the different ways of structuring grants, impacts the decision of homeowners to retrofit their homes. Table 6 shows the estimates of the parameters associated with the percentage of retrofit cost covered by the grant $x_{\text {GrantPerc }}$ and the maximum dollar amount that is covered by the grant $x_{\text {MaxGrant }}$. In addition, we also used our model results to calculate the choice probability of households making the decision to carry out structural retrofits on their homes. Assuming that each household is facing an actual choice about whether to carry out structural retrofits to their homes (i.e., a revealed-preference choice), we use the survey data and the parameter estimates from each model to calculate the utility of each individual assuming that they were offered a grant with differing percentage of retrofit cost covered $(0 \%, 50 \%$, and $100 \%)$, and different maximum cost covered $(\$ 2,500, \$ 5,000$, and $\$ 10,000)$. Because of our assumption, we do not consider either the state dependence or the scale difference between RP and SP data. These utilities are then used to calculate the choice probability of the individual, as in Eq. (4). The aggregate of the choice probabilities is reported in Fig. 1.

In line with Jasour et al. (2018), Ge et al. (2011), Poussin et al. (2014), and Vásquez and Mozumder (2017), we found that offering incentives does increase the probability that a homeowner will make the decision to retrofit their home. This is especially clear when looking at Fig. 1, where any grant offered results in a substantial increase in the probability that households choose to retrofit. Across the specifications and retrofit types, offering a grant results in a probability of retrofitting that is an average of 3 times as high as without a grant. Even the least generous grant (50\% up to $\$ 2,500)$ increases the retrofit probability by an average factor of 1.7 (from 1.3 for outlets/siding to 1.9 for piles). These results agree with hypotheses $\mathrm{H} 1$ and $\mathrm{H} 2$.

When looking specifically at the structure of grants, we found that increasing the percentage of the retrofit cost that is covered by the grant significantly increases the probability of retrofitting the home against all damage types (positive coefficient and $p<0.01$ for all models). As the coefficients of a mixed logit 
(a) Wind Damage to Roof

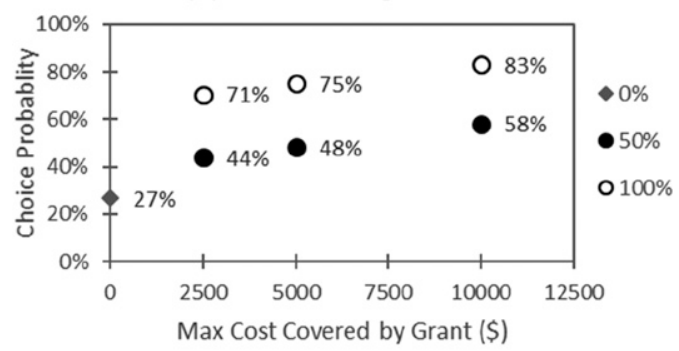

(c) Wind Damage to Roof-to-wall (Straps)

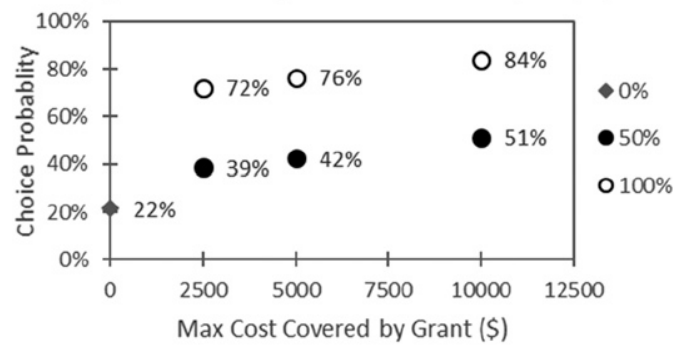

(e) Flood Damage to Home (Piles)

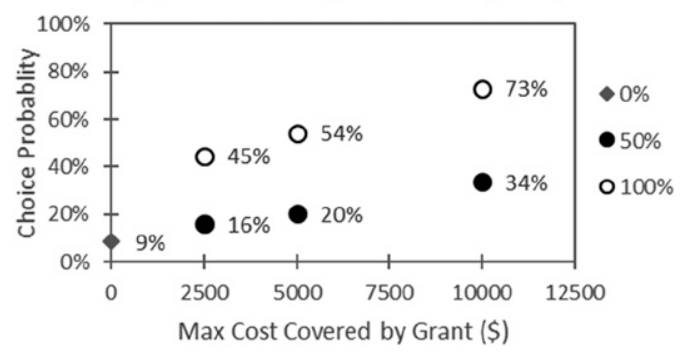

model are difficult to interpret, direct marginal effects were computed for the covariates that are statistically significant at $\alpha=0.1$ (Table 7). The direct marginal effect of a particular covariate for alternative $j$ is the effect that a unit increase in that covariate has on alternative $j$. Since the marginal effect for each observation is different, Hensher et al. (2015) recommends using the probability weighted sample enumeration method, where the weighted average of the observations is taken, with the weights defined as the choice probabilities.

The marginal effect results suggest that increasing the percentage of retrofit cost covered by the grant would substantially increase the probability of undertaking any (b) Wind Damage to Openings

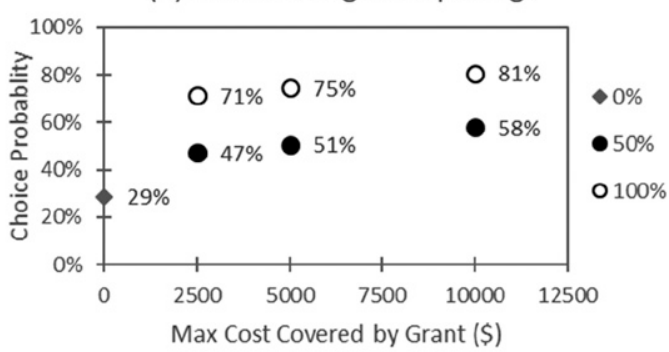

(d) Flood Damage to Outlets / Siding

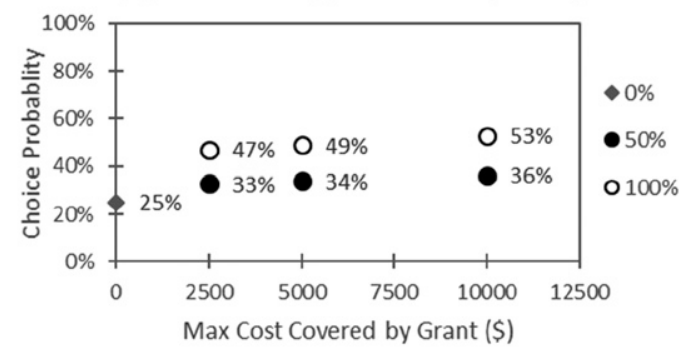

FIG. 1. Probability that household would retrofit based on percentage and maximum value of cost covered by grant.

TABLE 7. Marginal effects for covariates that are statistically significant at $\alpha=0.1$.

\begin{tabular}{|c|c|c|c|c|c|}
\hline Attribute & Roof & Openings & Straps & Outlets/siding & Piles \\
\hline Grant percentage $x_{\text {GrantPerc }}$ & 0.753 & 0.699 & 0.960 & 0.687 & 1.515 \\
\hline Max grant value $x_{\text {MaxGrant }}$ & 0.027 & 0.021 & 0.026 & 0.014 & 0.072 \\
\hline No. of hurricanes $x_{\text {num }}$ & -0.305 & & -0.360 & & -0.558 \\
\hline Distance from coastline $x_{\text {dist }}$ & -0.001 & -0.002 & -0.002 & -0.002 & -0.004 \\
\hline Age $x_{\text {age }}$ & -0.005 & -0.005 & -0.005 & -0.008 & -0.016 \\
\hline
\end{tabular}


is essentially a $100 \%$ increase in the retrofit cost that is covered by the grant.

Increasing the maximum cost covered by the grant also significantly increases the probability that the homeowner would retrofit their home in all models (positive coefficient; $p<0.1$ for outlets/siding model; $p<0.01$ for all other models). A unit increase $(\$ 1,000)$ in the maximum grant value leads to an increase of about $0.02-0.03$ in the probability of undertaking a retrofit to mitigate against wind damage. This effect is higher (0.07) for elevating homes. Again, this might be due to the cost of elevating a home on piles being much greater than that of the other retrofits, such that increasing the maximum cost covered by the grant would significantly affect how much the homeowner has to pay out of his/her own pocket. Alternatively, there might be some other nonmonetary reasons homeowners do not want to carry out retrofits, such as perceived time and effort involved (Lindell et al. 2009). Or they might find that installing hurricane straps or shutters will make the home look unattractive, such that even offering more money would not convince them to carry out these retrofits. These ideas offer areas of future study.

There are no combinations of grant structures that result in $100 \%$ of homeowners retrofitting their homes. Again, this indicates that there are other nonmonetary reasons or attributes of the structural retrofits that would cause homeowners to refuse to carry out structural retrofits. Additional research into these aspects would be useful for government agencies that aim to encourage homeowners to carry out hurricane damagemitigating retrofits.

\section{c. Impact of other covariates}

We find that the number of hurricanes experienced by a household $x_{\text {num }}$ has a significant negative effect on the probability that a household decides to strengthen their roof $(p<0.05)$, install hurricane straps $(p<0.05)$, and elevate their home on piles $(p<0.1)$ but no significant effect on the probability of undertaking other retrofits. This is similar in part to the conclusions drawn by Jasour et al. (2018) but contrary to Peacock (2003), Grothmann and Reusswig (2006), Petrolia et al. (2015), Ge et al. (2011), and hypothesis H3. While we hypothesized a positive effect, this negative effect might be due to the household thinking that if their house has gone through numerous hurricanes without requiring a lot of repairs, then they might become less likely to want to retrofit their homes, thinking that such retrofits are not necessary. There are many dimensions to the role of prior hazard event experience, such as the number and recentness of events, and the severity and nature of the event's impact (Demuth 2018). Sorting out the influence of each merits further study.

In line with Peacock (2003), Petrolia et al. (2015), Ge et al. (2011), Jasour et al. (2018), and hypothesis H4, a household's distance from the coastline, $x_{\text {dist }}$, had a significant negative impact ( $p<0.05$ for the roof model; $p<0.01$ for all other models) on the probability that a household decides to carry out structural retrofits in all hurricane damage models. However, counter to Poussin et al. (2014) and hypothesis H5 but in keeping with Jasour et al. (2018), we found no significant impact of a household's location in a floodplain $\left(x_{\mathrm{fp}}\right)$ on the decision to carry out structural retrofits against flood damage.

Contrary to Peacock (2003), Grothmann and Reusswig (2006), Jasour et al. (2018), Ge et al. (2011), and hypothesis H6, but in keeping with Petrolia et al. (2015) and Poussin et al. (2014), we found no significant impact of income $\left(x_{\text {inc }}\right)$ on the likelihood that households would implement structural retrofits. This is an interesting finding especially when taken in combination with the result that when offered money (through grants), homeowners are more incentivized to carry out structural retrofits to their homes. This result might suggest that homeowners do not feel they have disposable income to spend on mitigation (Petrolia et al. 2015), but if provided with money that does not need to be returned, they are willing to implement the retrofit. Of course, a lack of evidence in this sample does not necessarily indicate a relationship does not exist, just that it was not evident in this analysis.

In line with Ge et al. (2011), hypothesis H7, and partially with Jasour et al. (2018), but contrary to Poussin et al. (2014), Grothmann and Reusswig (2006), and Peacock (2003), we find that age $x_{\text {age }}$ has a significant negative effect ( $p<0.1$ for the straps model, $p<0.01$ for the piles model, and $p<0.05$ for all other models) on the probability of carrying out structural retrofits. Counter to hypothesis $\mathrm{H} 8$, the expected future tenure $\left(x_{\text {futtenure }}\right)$ was not found to have any significant impact on the probability of carrying out retrofits on the home.

\section{Conclusions}

In this paper, we extended the work of Jasour et al. (2018) by using a new dataset and focusing on the impact that different government grants have on the likelihood that a household will carry out structural retrofits to mitigate against wind and flood damage caused by hurricanes. We combined revealed- and stated-preference data and developed separate mixed logit models that address five different types of hurricane damage.

Multiple state and local programs (as described in section 2) now offer monetary incentives to encourage 
homeowners to strengthen their homes so as to minimize damage from natural hazard events. Nevertheless, there has been little study of the influence of these incentives on homeowner decision-making. As such programs are developed and expanded, it will be important to understand how much should be spent on such programs, how effective they are at increasing retrofits and reducing risk, and how they can be best structured and targeted so as to maximize their positive effect. This study adds to the modest literature on the topic by focusing on the effect of grants on hurricane damage.

Our analysis indicates that offering a homeowner a grant significantly increases the probability that he will retrofit his home. In addition, increasing the percentage of retrofit cost covered by the grant or the total amount of the grant both result in homeowners being more likely to retrofit their homes, with the former having a greater impact on this probability. In the end, the best grant program structure depends on the government budget and the relative costs of increasing the percentage and maximum grant amount in addition to the effect of each of those parameters on homeowner retrofit rates.

The results also indicate that there is no grant structure that would likely convince every homeowner to retrofit their house and that the retrofit rates vary by specific retrofit type (e.g., strengthening roof vs protecting openings). This suggests the important conclusion that there may be other nonmonetary aspects that influence a homeowner's retrofit decision in addition to cost. Finally, our models suggest that there is a tendency for homeowners to be less likely to retrofit their homes if they have experienced more than one hurricane.

As with any study, there are limitations that require note as we interpret the results and point to areas of future study. First, the analysis would be improved with a larger sample that extends across a larger geographic region and includes better representation of nonwhite residents. The occurrence of Hurricane Matthew a few months before the survey also may have influenced the responses in ways that are difficult to test without expanding the sample. Second, the suggestion that nonmonetary attributes of the retrofits themselves (as opposed to the homeowners) may influence their adoption merits further study. It would be helpful to understand which additional attributes are important. For example, if understanding how the retrofit works is important, that might suggest additional education efforts, or if the effect on a home's attractiveness is important, it may suggest new designs or focus on other types of retrofits. Third, the role of prior experience of hazard events deserves more attention to determine which aspects of the experience-recentness, frequency, intensity, or type-if any, influence retrofit decisions. Last, this analysis focused on the effect of monetary incentives on homeowner decisions related to their existing homes, but similar analyses could be conducted to investigate the possible influence of economic incentives to encourage construction that exceeds building code standards at the time of construction or the possible influence of economic incentives for developers rather than homeowners.

Acknowledgments. This material is based on work supported by the National Science Foundation under collaborative Awards 1435298, 1433622, and 1434716 and the U.S. Department of Homeland Security under Grant Award 2015-ST-061-ND0001-01. The statements, findings, and conclusions are those of the authors and do not necessarily reflect the views of the U.S. Department of Commerce, the National Science Foundation, or the U.S. Department of Homeland Security.

\section{REFERENCES}

AAPOR, 2019: Response rates-An overview. American Association for Public Opinion Research, accessed 20 May 2019, https://www.aapor.org/Education-Resources/For-Researchers/ Poll-Survey-FAQ/Response-Rates-An-Overview.aspx.

Alabama Association of Realtors, 2019: Strengthen Alabama Homes-Making a difference. Accessed 21 May 2019, https:// www.alabamarealtors.com/posts/4116.

Alabama Department of Insurance, 2014: What is FORTIFIED? Accessed 21 May 2019, https://www.aldoi.gov/SAH/Documents/ FORTIFIED\%20Insurance\%20Discount\%20Chart.pdf.

_ 2018: Strengthen Alabama Homes. Accessed 2 November 2018, https://strengthenalabamahomes.com/.

Bhat, C. R., and S. Castelar, 2002: A unified mixed logit framework for modeling revealed and stated preferences: Formulation and application to congested pricing analysis in the San Francisco Bay area. Transp. Res., 36B, 593-616, https:// doi.org/10.1016/S0191-2615(01)00020-0.

Binder, S. B., and A. Greer, 2016: The Devil is in the details: Linking home buyout policy, practice and experience after Hurricane Sandy. Polit. Governance, 4 (4), 97-106, https:// doi.org/10.17645/pag.v4i4.738.

Börjesson, M., 2008: Joint RP-SP data in a mixed logit analysis of trip timing decisions. Transp. Res., 44E, 1025-1038, https:// doi.org/10.1016/j.tre.2007.11.001.

Boxall, P. C., J. Englin, and W. L. Adamowicz, 2003: Valuing aboriginal artifacts: A combined revealed-stated preference approach. J. Environ. Econ. Manage., 45, 213-230, https:// doi.org/10.1016/S0095-0696(02)00063-3.

Brownstone, D., D. S. Bunch, and K. Train, 2000: Joint mixed logit models of stated and revealed preferences for alternative-fuel vehicles. Transp. Res., 34B, 315-338, https://doi.org/10.1016/ S0191-2615(99)00031-4.

Colorado Department of Revenue, 2018: Income 65: Wildfire mitigation measures subtraction. Accessed 2 November 2018, https://www.colorado.gov/pacific/sites/default/files/ Income65.pdf.

Demuth, J. L., 2018: Explicating experience: Development of a valid scale of past hazard experience for tornadoes. Risk Anal., 38, 1921-1943, https://doi.org/10.1111/ risa.12983. 
Dillman, D. A., 2007: Mail and Internet Surveys: The Tailored Design Method. 2nd ed. John Wiley and Sons, 565 pp.

Ehrlich, I., and G. S. Becker, 1972: Market insurance, self-insurance, and self-protection. J. Polit. Econ., 80, 623-648, https://doi.org/ 10.1086/259916.

Florida Division of Emergency Management, 2014: Hurricane Loss Mitigation Program 1997-2014. Accessed 21 May 2019, https:// www.sbafla.com/fhcf/Portals/FHCF/Content/AdvisoryCouncil/ 2014/1014/20141014_RCMP_Handout.pdf?ver=2016-06-08091005-443.

— 2018: Hurricane Loss Mitigation Program. Accessed 5 July 2018, https://www.floridadisaster.org/dem/mitigation/hurricaneloss-mitigation-program/.

Ge, Y., W. G. Peacock, and M. K. Lindell, 2011: Florida households' expected responses to hurricane hazard mitigation incentives. Risk Anal., 31, 1676-1691, https://doi.org/ 10.1111/j.1539-6924.2011.01606.x.

Grothmann, T., and F. Reusswig, 2006: People at risk of flooding: Why some residents take precautionary action while others do not. Nat. Hazards, 38, 101-120, https://doi.org/10.1007/s11069005-8604-6.

Harrell, F., 2015: Regression Modeling Strategies: With Applications to Linear Models, Logistic and Ordinal Regression, and Survival Analysis. 2nd ed. Springer, 582 pp.

Hensher, D. A., and M. Bradley, 1993: Using stated response choice data to enrich revealed preference discrete choice models. Mark. Lett., 4, 139-151, https://doi.org/10.1007/BF00994072.

, J. M. Rose, and W. H. Greene, 2008: Combining RP and SP data: Biases in using the nested logit 'trick'-Contrasts with flexible mixed logit incorporating panel and scale effects. J. Transp. Geogr., 16, 126-133, https://doi.org/10.1016/ j.jtrangeo.2007.07.001.

_ - _ , and 2015: Applied Choice Analysis. 2nd ed. Cambridge University Press, 1216 pp.

IBHS, 2018: Regulatory framework for FORTIFIED insurance incentives. Accessed 30 September 2019, https://disastersafety.org/ wp-content/uploads/FORTIFIED-Home-Incentives_IBHS.pdf.

Jasour, Z. Y., R. Davidson, J. Trainor, J. Kruse, and L. Nozick, 2018: Homeowner decisions to retrofit to reduce hurricaneinduced wind and flood damage. J. Infrastruct. Syst., 24 04018026, https://doi.org/10.1061/(ASCE)IS.1943-555X.0000452.

Javeline, D., and T. Kijewski-Correa, 2019: Coastal homeowners in a changing climate. Climatic Change, 152, 259-274, https:// doi.org/10.1007/s10584-018-2257-4.

Kousky, C., 2017: Disasters as learning experiences or disasters as policy opportunities? Examining flood insurance purchases after hurricanes. Risk Anal., 37, 517-530, https://doi.org/ 10.1111/risa.12646.

Kunreuther, H., 2016: Reducing losses from catastrophes: Role of insurance and other policy tools. Environment, 58 (1), 30-37, https://doi.org/10.1080/00139157.2016.1112166.

Lavasani, M., M. D. Hossan, H. Asgari, and X. Jin, 2017: Examining methodological issues on combined RP and SP data. Transp. Res. Procedia, 25, 2330-2343, https://doi.org/10.1016/ j.trpro.2017.05.218.

Lindell, M. K., and R. W. Perry, 2012: The protective action decision model: Theoretical modifications and additional evidence. Risk Anal., 32, 616-632, https://doi.org/10.1111/j.15396924.2011.01647.x.

_ S. Arlikatti, and C. Prater, 2009: Why people do what they do to protect against earthquake risk: Perceptions of hazard adjustment attributes. Risk Anal., 29, 1072-1088, https://doi.org/ 10.1111/j.1539-6924.2009.01243.x.
Louisiana Department of Insurance, 2005: Residential property storm mitigation incentives. Accessed 2 November 2018, https:/www.ldi.la.gov/docs/default-source/documents/publicaffairs/ consumerpublications/residential_property_storm_mitigation.pdf? sfvrsn=bf947c52_20.

Louviere, J. J., D. A. Hensher, and J. D. Swait, 2000: Stated Choice Methods: Analysis and Applications. Cambridge University Press, 420 pp.

Marketing Systems Group, 2018: GENESYS. Accessed 28 November 2018, https://www.m-s-g.com/Pages/genesys/.

McAneney, J., D. McAneney, R. Musulin, G. Walker, and R. Crompton, 2016: Government-sponsored natural disaster insurance pools: A view from down-under. Int. J. Disaster Risk Reduct., 15, 1-9, https://doi.org/10.1016/j.ijdrr.2015.11.004.

Miles, A., 2016: Obtaining predictions from models fit to multiple imputed data. Sociol. Methods Res., 45, 175-185, https:// doi.org/10.1177/0049124115610345.

NCIUA, 2017: Services and coverages. North Carolina Insurance Underwriting Association, accessed 20 May 2019, http:// www.ncjua-nciua.org/html/svcs_cov.htm.

Peacock, W. G., 2003: Hurricane mitigation status and factors influencing mitigation status among Florida's single-family homeowners. Nat. Hazards Rev., 4, 149-158, https://doi.org/ 10.1061/(ASCE)1527-6988(2003)4:3(149).

Petrolia, D. R., J. Hwang, C. E. Landry, and K. H. Coble, 2015: Wind insurance and mitigation in the coastal zone. Land Econ., 91, 272-295, https://doi.org/10.3368/le.91.2.272.

Porter, K., and Coauthors, 2017: Natural hazard mitigation saves: 2017 interim report. National Institute of Building Sciences Rep., 344 pp., http://www.wbdg.org/files/pdfs/MS2_2017Interim\%20Report.pdf.

Poussin, J. K., W. J. W. Botzen, and J. C. J. H. Aerts, 2013: Stimulating flood damage mitigation through insurance: An assessment of the French CatNat system. Environ. Hazards, 12, 258-277, https://doi.org/10.1080/17477891.2013.832650.

, — - and — 2014: Factors of influence on flood damage mitigation behavior by households. Environ. Sci. Policy, 40, 69-77, https://doi.org/10.1016/j.envsci.2014.01.013.

Ramirez, K., 2017: Here's what today's first-time homebuyer looks like. Housingwire, accessed 22 May 2019, www.housingwire.com/ articles/41813-heres-what-todays-first-time-homebuyer-lookslike.

SCONC, 2019: Hurricanes. North Carolina State University State Climate Office of North Carolina, accessed 20 May 2019, https://climate.ncsu.edu/climate/hurricanes/statistics.

South Carolina Department of Insurance, 2018: SC Safe Home Grant. Accessed 2 November 2018, http://www.doi.sc.gov/ 895/Apply-for-a-Grant.

__ 2019: 2018 status report on the South Carolina coastal property insurance market. SCDI Rep., 54 pp., https:// doi.sc.gov/DocumentCenter/View/11376/2018-Status-Reporton-the-South-Carolina-Coastal-Property-Insurance-Market?bidId=.

Swait, J., J. J. Louviere, and M. Williams, 1994: A sequential approach to exploiting the combined strengths of SP and RP data: Application to freight shipper choice. Transportation, 21, 135-152, https://doi.org/10.1007/BF01098789.

Thieken, A. H., T. Petrow, H. Kreibich, and B. Merz, 2006: Insurability and mitigation of flood losses in private households in Germany. Risk Anal., 26, 383-395, https://doi.org/10.1111/ j.1539-6924.2006.00741.x.

Train, K. E., 2009: Discrete Choice Methods with Simulation. 2nd ed. Cambridge University Press, 378 pp.

van Buuren, S., 2012: Flexible Imputation of Missing Data. Chapman and Hall/CRC Press, 342 pp. 
, and K. Groothuis-Oudshoorn, 2011: mice: Multiple imputation by chained equations in R. J. Stat. Software, 45 (3), 1-67, https://doi.org/10.18637/jss.v045.i03.

Vásquez, W. F., and P. Mozumder, 2017: Willingness to pay for hurricane-resistant home improvement programs: A choice experiment in northeastern and mid-Atlantic United States. Econ. Disasters Climate Change, 1, 263-276, https://doi.org/ 10.1007/s41885-017-0016-z.

Wang, D., R. A. Davidson, J. E. Trainor, L. K. Nozick, and J. Kruse, 2017: Homeowner purchase of insurance for hurricane-induced wind and flood damage. Nat. Hazards, $\mathbf{8 8}$, 221-245, https://doi.org/10.1007/s11069-017-2863-x.

White, I. R., P. Royston, and A. M. Wood, 2011: Multiple imputation using chained equations: Issues and guidance for practice. Stat. Med., 30, 377-399, https://doi.org/10.1002/sim.4067.

Whitehead, J.C., S. K. Pattanayak, G. L. Van Houtven, and B. R. Gelso, 2008: Combining revealed and stated preference data to estimate the nonmarket value of ecological services: An assessment of the state of the sciences. J. Econ. Surv., 22, 872908, https://doi.org/10.1111/j.1467-6419.2008.00552.x. 